\title{
Permanencia ARQUITECTÓNICA DE LA HAGIENDA DE NUESTRA SEÑORA DE LOS REMEDIOS
}

\author{
Architectural permanence of the Hacienda de Nuestra Señora de los Remedios
}

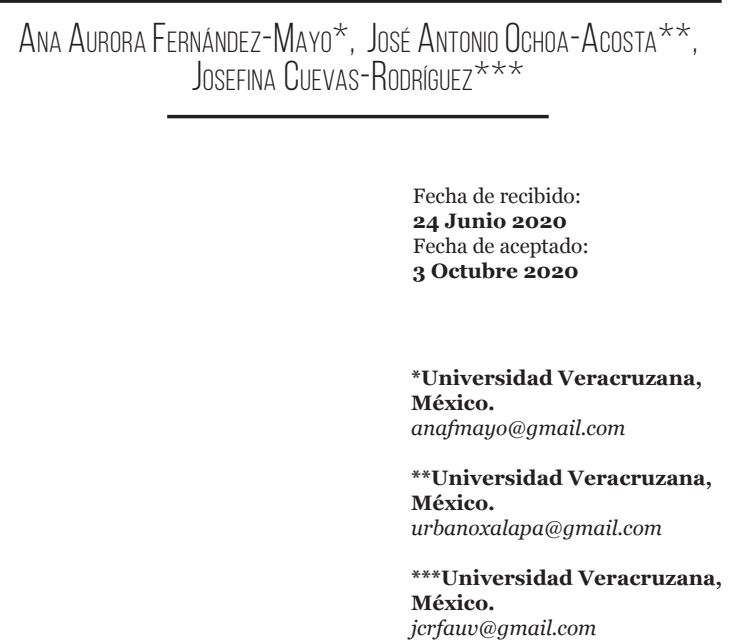

RESUMEN. La Hacienda de Nuestra Señora de los Remedios es uno de los mejores inmuebles conservados en la zona central del estado de Veracruz, México, cuya construcción muestra la permanencia arquitectónica del territorio hacendario y la sobrevivencia de la reforma agraria, que la convirtió en un terreno de propiedad social, forzada también a cambiar sus cañaverales en cafetales debido a las dificultades económicas presentadas en 1922. Las haciendas, consideradas patrimonio cultural arquitectónico, representan la etapa de desarrollo histórico, político y económico que destacan los patrones territoriales del estado de Veracruz. Caracterizadas como unidades económicas, las haciendas potencializaron la mejora del medio rural al establecerse como entidades productivas alrededor de las cuales se desarrollaron pequeños grupos de asentamientos humanos, que identificaron a cada región en una determinada época y periodo de producción a partir de la funcionalidad y la configuración del espacio arquitectónico con el entorno donde estaban asentadas.

El presente artículo describe un estudio de la Hacienda de Nuestra Señora de los Remedios como patrimonio cultural y su permanencia arquitectónica en la actualidad. De esta manera, el análisis histórico del conjunto de la Hacienda y los inmuebles que la componen proporciona una serie de evidencias de la relación existente entre el grado de conservación del inmueble y las funciones inmutables, que le confiere la comunidad a la que pertenece, hecho que destaca la importancia de su preservación.

Palabras clave: análisis histórico, arquitectura, medio rural, patrimonio cultural.
ABSTRACT. The Haciendas, considered Architectural Cultural Heritage, represent the stage of historical, political and economic development highlighted by the territorial patterns of the State of Veracruz. Characterized as economic units, the haciendas potentiated the improvement of the rural environment by establishing themselves as productive entities around which small groups of human settlements developed that identified each region at a certain time and period of production based on the functionality and the configuration of the architectural space with the environment where they were settled. The Hacienda de Nuestra Señora de los Remedios is one of the best preserved buildings in the central area of the state of Veracruz, Mexico, whose construction shows the architectural permanence of the hacienda territory and is a survivor of the agrarian reform that turned it into social property, also forced to change its sugarcane fields into coffee plantations due to the economic difficulties presented in 1922.

The research presented in this document describes a study of the Hacienda de Nuestra Señora de los Remedios as cultural heritage and its architectural permanence today. In this way, the historical analysis of the whole of the Hacienda and the properties that compose it provides a series of evidences of the relationship between the degree of conservation of the property and the immutable functions conferred by the community to which it belongs, a fact that highlights the importance of its preservation.

Key words: historical analysis, architecture, rural environment, cultural heritage. 


\section{CONSERVACIÓN DE LAS HACIENDAS}

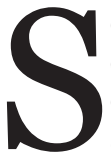

e menciona la importancia de la conservación de la Hacienda en estudio a partir de la exposición de algunas perspectivas de postulados e investigaciones relacionadas al patrimonio cultural en virtud de la categorización en la que recae el inmueble hacendario y al buen estado de conservación del inmueble (figura 1), que acentúa la importancia de la Hacienda de Nuestra Señora de los Remedios como patrimonio cultural, con un alto grado de identidad social y arquitectónica en la región donde se encuentra asentada.

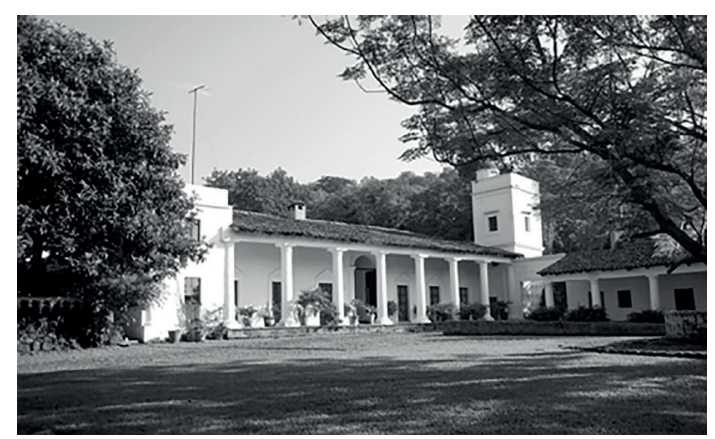

FIGURA 1. CONJUNTO DE LA HACIENDA DE NUESTRA SEÑORA DE LOS REMEDIOS EN PACHO (2009)

FUENTE: GERARDO SÁNCHEZ VIGLL

En este sentido, se destacan las consideraciones que la Organización de las Naciones Unidas para la Educación, la Ciencia y la Cultura (UNESCO, por sus siglas en inglés) en su 15a reunión, celebrada en París, presenta como medidas de conservación y salvación del patrimonio cultural (UNESCO, 1968):

- Las medidas orientadas a la conservación de los bienes culturales requieren tomarse en cuenta en la planeación y ejecución de las obras públicas o privadas.

- La ejecución de obras públicas o privadas que puedan poner en peligro los bienes culturales deben considerar medidas apoyadas en la legislación de cada país.

- Los Estados Miembros deben dar prioridad a las medidas necesarias para la conservación in situ de los bienes culturales que corran peligro para mantener la continuidad y las vinculaciones históricas de tales bienes.

- Asimismo, en cada país se deben tomar las medidas necesarias para fomentar entre sus ciudadanos el interés y el respeto por el patrimonio cultural del pasado $\mathrm{y}$ sus tradiciones, que promuevan la conservación y salvaguarda de sus bienes culturales.

Asimismo, el Laboratorio de Arqueología y Arquitectura de la Ciudad (LAAC, 2016) de España, menciona que la idea de la conservación del Patrimonio conlleva la preservación de un conjunto de valores históricos o simbólicos que justifican su trascendencia, es decir, la importancia de su permanencia no se basa en los bienes materiales que lo integran, sino en considerar aspectos físicos e inmateriales que representan un conjunto integral de los bienes de una colectividad. Por ello, se considera que, aunado a lo anterior, es importante el estudio de intervención histórica para que el objetivo de conservación del edificio se cumpla a fin de mantenerlo en su estado original.

Es importante comprender cuál es la relevancia de la conservación en los monumentos históricos, tal es el caso de estudio que aquí se presenta, considerando que el propósito de conservar un monumento tiene un valor específico que enfatiza el uso que anteriormente se le dio, es decir, la funcionalidad del edificio para mantener en un estado de habitabilidad el inmueble en cuestión, tal y como se construyó. 
A lo largo de la historia de México, en específico del estado de Veracruz, diversos acontecimientos históricos, políticos y económicos marcaron los patrones territoriales, que en la actualidad son características de las haciendas. Durante los siglos (S.) xVIII y xIX, las haciendas se convirtieron en la principal unidad económica, política y social en el ambiente rural del territorio veracruzano, cuyo sistema productivo determinóla creación de pequeños asentamientos humanos en torno a estas entidades productivas.

Las haciendas ${ }^{1}$ fueron un sistema económico que, a principios del siglo xx, surgen como parte del Movimiento Agrario, ${ }^{2}$ lo cual llevó a la parcelación y repartición de tierra para trabajadores y pobladores de las comunidades aledañas. En consecuencia, el territorio fue reordenado y surgieron nuevas formas de apropiación de la propiedad para dar lugar a los ejidos. Dichos espacios desaparecieron como unidad económica, este modelo de apropiación de la tierra creó un paisaje, una configuración que correspondió a una determinada época, enraizado en un medio natural y social. Meyer establece que "la hacienda, como unidad arquitectónica, configuró un paisaje que corresponde a la modernidad de una determinada época, si se acepta la pérdida de estos espacios, significa que cierta visión llegó a su fin” (1992: viII).

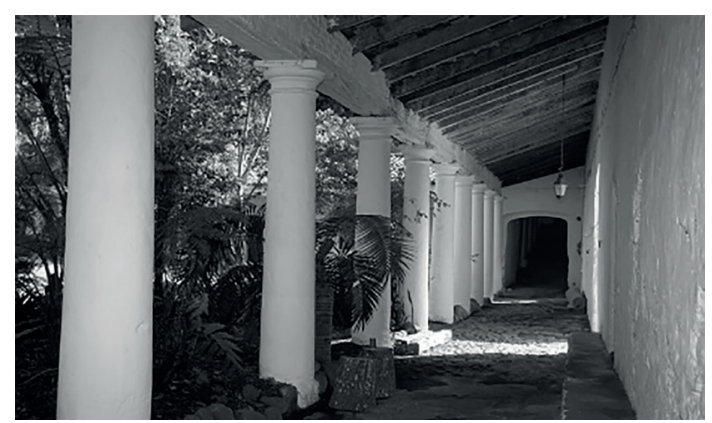

FIGURA 2. PASILLO DE LA HACIENDA DE NUESTRA SEÑORA DE LOS REMEDIOS ENPACHO (2009)

FUENTE: GERARDO SÁNCHEZ VIGLL.

\section{CONSERVACIÓN DE LA HACIENDA DE NUESTRA SEÑORA DE LOS REMEDIOS}

Este inmueble fue construido, en 1592, por encargo de Don Juan de Quiroz y Don Sebastián Díaz, con la finalidad de sembrar y moler caña de azúcar en una propiedad del señor Quiroz, denominada Nexapa. La hacienda fue adquirida en el siglo XVII por el Sr. D. Luis Pacho y Mexía, de donde retoma el nombre de Hacienda de Pacho, quien administró la propiedad hasta su muerte. Posteriormente en el siglo XVIII, fue administrada por Jesuitas, que a fin de siglo la convirtieron en una de las haciendas más extensas de la región con casi 1200 hectáreas de superficie. Desde entonces ha tenido una gran cantidad de propietarios y copropietarios entre los cuales se incluye la iglesia y terratenientes locales, nacionales y extranjeros (Bermúdez, 1988).

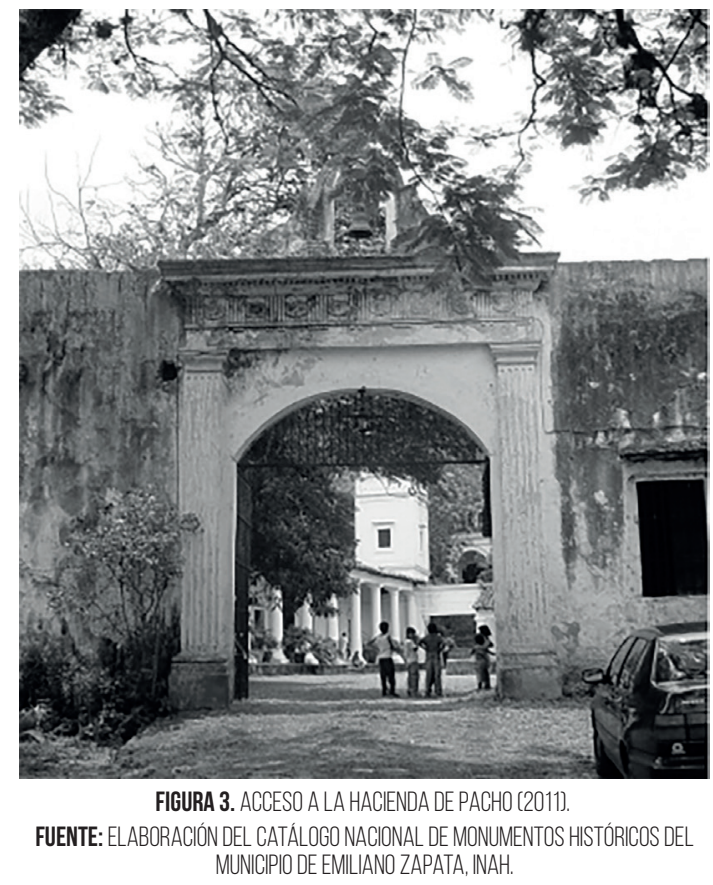

A mediados del siglo XIX es comprada por el Señor José Julián Gutiérrez y Fernández, amigo muy cercano del presidente Antonio López de Santa Anna. La familia Gutiérrez es, desde entonces, propietaria de la hacienda, sin embargo, a partir del reparto agrario la propiedad perdió una superficie de 712 hectáreas (Cambrezy, 1992), pero conservó el casco histórico y espacios arquitectónicos importantes que hacen que su funcionalidad esté vigente. En las figuras 2 y 3 se observa el pasillo y el acceso a la Hacienda de Pacho que muestran, en la actualidad, un buen estado de conservación.

En este desarrollo histórico, se precisa que, debido a los cambios generados por 


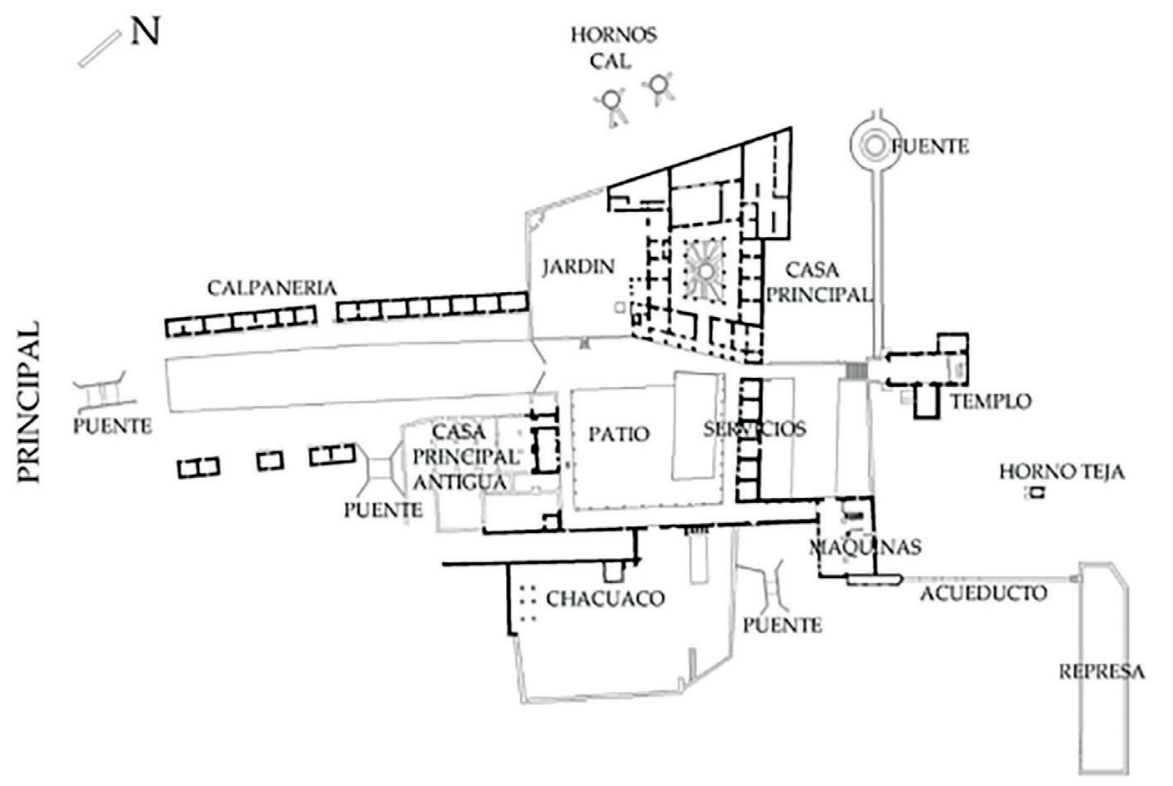

FIGURA 4. PLANO DE LA HACIENDA DE PACHO (2011).

FUENTE:ELABORACIÓN DEL CATÁLOGO NACIONAL DE MONUMENTOS HISTÓRICOS DEL MUNIIIIO DE EMLLIANO ZAPATA, INAH.

los acontecimientos políticos y sociales del país, y en específico de la región en donde se asienta este inmueble, hacia 1770 el trapiche y molienda de la hacienda se habían convertido en rancho de ganado mayor, que fue otro giro productivo al iniciar y se le dio el nombre de San Cayetano Pacho. Durante 60 años hubo una transformación económica debido al auge que le dio nuevamente el cultivo de la caña de azúcar. La casa y el trapiche estaban distribuidas de manera que albergaban espacios suficientes para el proceso de producción y albergue de personal, entre ellos, dueños y trabajadores, unos en algún tiempo fueron esclavos traídos del extranjero. La distribución de la hacienda la ocupaba una casa de calderas, moliendas, bodegas para guardar azúcar y astillero para la leña, una casa de purga y bodega para maíz unidos por un corredor. La vivienda constaba de dos partes, cada una con un zaguán, dos salas, dos recámaras, tres cuartos y baño, caballería, patio y jardín, espacios que, en conjunto, muestran el partido arquitectónico del inmueble dándole un carácter de hacienda virreinal caracterizada por los elementos formales y funcionales de su época de desarrollo (García, M., 1983).

Esta hacienda constituye uno de los mejores ejemplos de la arquitectura para la producción del periodo virreinal de la región de Xalapa y Coatepec. Gran parte de sus elementos arquitectónicos se encuentran bien conservados, lo que hace destacar su importancia como objeto arquitectónico relevante y como parte de un sistema de haciendas que potenció el desarrollo económico de la época virreinal y de la región de Pacho, donde se asienta.
La figura 4 muestra el plano de la Hacienda donde se aprecia la composición del partido arquitectónico.

\section{VESTIGIOS DE UN PASADO}

La importancia histórica de la hacienda, aunada a la cultural y patrimonial, radica en la relación formal y funcional de la hacienda con el proceso de producción, que transformó la economía del entorno, además de la importancia social y cultural por la que se conoce la Hacienda de Nuestra Señora de los Remedios, antes San Cayetano (alias) Pacho, que fue una hacienda azucarera, cuya fundación se remonta hacia el siglo Xvi y que, durante tres siglos, se mantuvo de pie y logró conservar sus tierras para la producción agrícola que sostuvo a un singular número de familias de los trabajadores de la región.

Con relación a la parte arquitectónica y como se mencionó en el apartado anterior, el análisis realizado hace énfasis en la composición, cuya distribución de la vivienda destaca al conjunto central como espacio primordial. Este conjunto se forma de la casa principal, la casa de servidumbre y la casa antigua, dichos inmuebles contienen corredores porticados que rodean el patio central del complejo resaltando su arquitectura virreinal. Asimismo, el patio central cuenta con una fuente monumental que funciona con el agua, que baja desde un manantial, el cual proveía del vital líquido a los habitantes y trabajadores para la realización de las actividades y necesidades de la casa y zona productiva. En el conjunto también se localizan otros dos patios de 
menor tamaño, tres puentes, una chimenea (o chacuaco), hornos de cal y de teja, así como el acueducto y la represa que permitían el proceso productivo de los productos agrícolas (García, M., 1983).

El acceso al conjunto es un camino empedrado y flanqueado por las casas de los trabajadores. La portada se compone de pilastras dóricas y un dintel neoclásico rematado por una espadaña con campana y florones en la esquina.

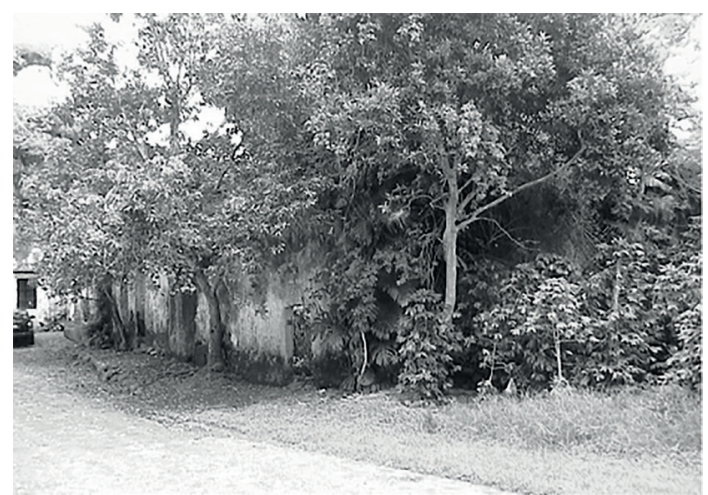

FIGURA 5. CASA ANTIGUA, HACIENDA DE PACHO (2011).

FUENTE:ELABORACIÓN DEL CATÁLOGO NACIONAL DE MONUMENTOS HISTÓRICOS DEL MUNICIPIO DE EMLIIANO ZAPATA, INAH.

La casa antigua, construida en 1843, se encuentra en ruinas (figura 5) (Cambrezy, 1992). Su planta es de una sola crujía y sólo tres espacios frontales que aún cuentan con una cubierta de viguería de madera y pisos de mazarín, que actualmente se usan como bodegas. La fachada, lisa de color blanca, se compone de seis vanos; el vano más grande tiene forma de arco de medio punto y conduce a la parte posterior de las bodegas, que cuentan con tres puertas de acceso. Este edificio, al igual que el resto de los inmuebles del conjunto, contaba con un corredor delimitado por columnas sin base y con capitel de molduras sencillas.

La casa principal (figura 6) es un inmueble con planta en forma de "C", donde el acceso se localiza hacia el patio central del conjunto,

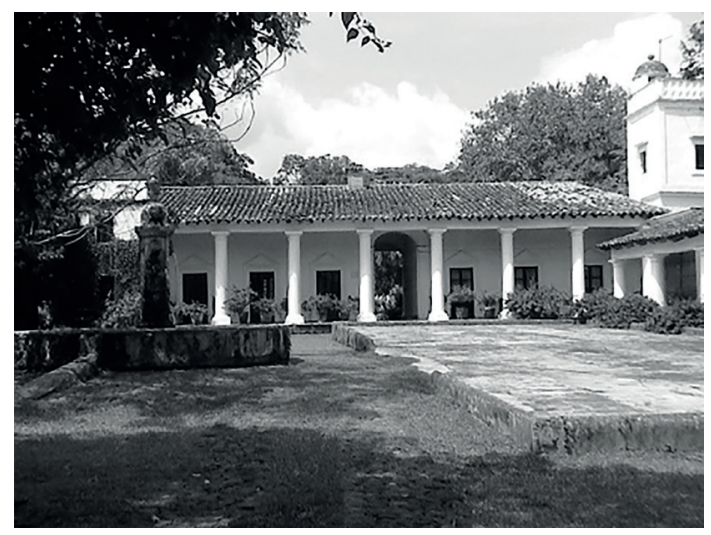

FIGURA 6. CASA PRINCIPAL, HACIENDA DE PACHO (2011).

FUENTE: ELABORACIÓN DEL CATÁLOGO NACIONAL DE MONUMENTOS HISTÓRICOS DEL MUNICPIO DE EMLLIANO ZAPATA, INAH esta área consta de antesala, seis habitaciones, un baño, área de cocina y servicio, comedor y sala principal que a continuación se muestra.

Esta casa tiene un pasillo que conduce al patio central interior de la misma, donde la antesala es un alto corredor porticado con ocho columnas esbeltas con base y capitel de molduras sencillas. Los espacios del patio interior están dispuestos en torno al jardín y se accede a ellos a través de un corredor que lo rodea. Los muros son de mampostería de piedra, la cubierta inclinada a dos aguas de viguería de madera con mazarán, tablas y tejas y los pisos de mazarín. Estas características permiten considerar a este inmueble como el mejor conservado del conjunto.

Hacia el sureste, y a un costado del corredor del acceso principal, se localiza una torrecilla, cuyo uso original es desconocido, no obstante, hoy en día se usa como baño y vestidor de la propietaria. Dicho elemento puede ser el testimonio más representativo del periodo jesuita de la hacienda.

La Capilla aún es visitada con frecuencia por habitantes de la localidad, se ubica hacia el extremo noreste del conjunto en una zona elevada del terreno, detrás de la casa principal y de la casa de servidumbre; es un inmueble con planta de una sola crujía y capilla lateral.

El pórtico (figura 7) está delimitado por la portada y la escalinata, la fachada muestra una portada exenta rematada por una espadaña y cubierta de viguería de madera y teja. Las columnas que forman la portada son de estilo dórico y sostienen el entablamento sobre el que descansa la espadaña, se compone de un tímpano semicircular con roleos en su parte centro-superior. En el tímpano se tienen tres arcos de medio punto, donde se ubica el espacio que contenía a tres campanas de los

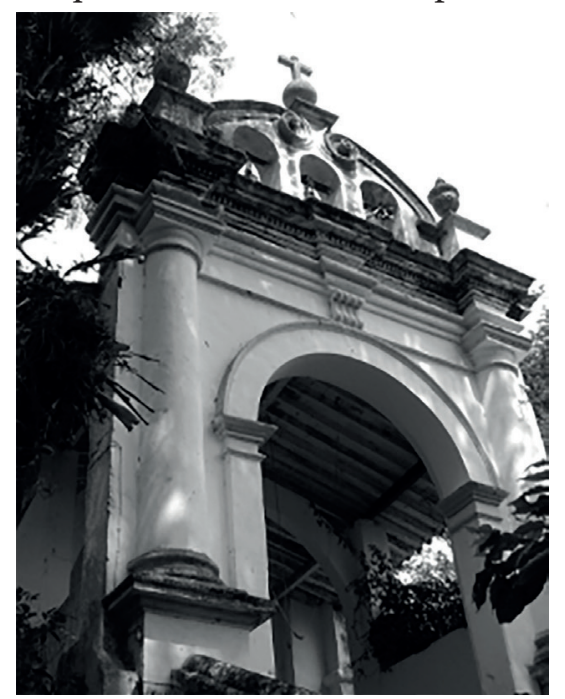

FIGURA 7. PÓRTICO DE LA CAPLLLA DE NUESTRA SEÑORA DE LOS REMEDIOS, HACIENDA DE PACHO (2011).

FUENTE: ELABORACIÓN DEL CATÁLOGO NACIONAL DE MONUMENTOS HISTÓRICOS DEL MUNICIPIO DE EMILIANO ZAPATA, INAH. 
años 1777,1800 y 1797. Al seguir el eje de las columnas, se tienen en el remate dos florones y sobre los roleos un orbe coronado con cruz.

El cuerpo principal de la capilla se forma por una nave de cuatro tramos y rematada al fondo por un ábside de forma rectangular. Se resguarda por una cubierta inclinada a dos aguas de viguería de madera con tablas, mazarín y teja. Los muros son de mampostería de piedra con aplanados de calarena, mientras la fachada interior es lisa; el acceso es un arco rebajado, cuenta con dos altares, uno en el ábside de la nave principal y el otro en la capilla lateral.

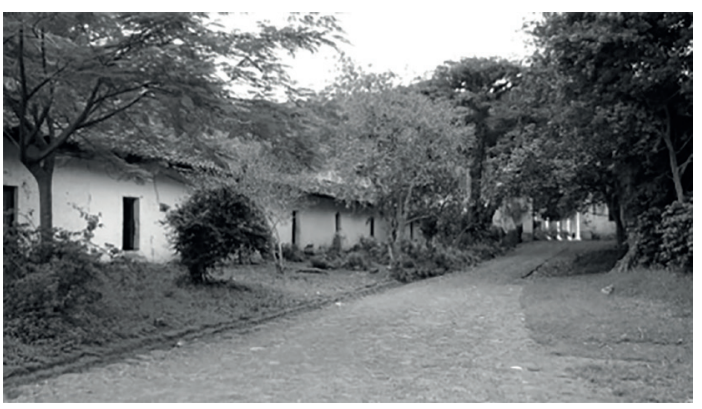

FIGURA 8. CALPANERIÁA IZQUIEERDA DE LA HACIENDA DE PACHO (2011). FUENTE: ELABORACIÓN DEL CATÁLOGO NACIONAL DE MONUMENTOS HISTÓRICOS DEL MUNICIPIO DE EMILIANO ZAPATA, INAH.

La calpanería (figura 8) funge como antesala de la reja principal de acceso al casco; se encuentra previa a la entrada principal, rumbo al suroeste. Esta unidad se compone de cinco estructuras de mampostería de piedra con aplanado color blanco, techumbre de viguería de madera y teja. Tres inmuebles se ubican al lado izquierdo del camino empedrado que lleva a la reja principal y dos a la derecha. Su proceso constructivo es básico y sencillo, el estado de conservación del conjunto al exterior es bueno, pero al interior en algunos casos es muy deteriorado por falta de mantenimiento de sus moradores.

El total del conjunto comprende 22 viviendas, las cuales han sido ocupadas por descendientes de extrabajadores. En la actualidad se encuentran habitadas cinco viviendas, aunque se tienen catorce viviendas repartidas en tres módulos de ocho, tres y tres viviendas unifamiliares a la izquierda $\mathrm{y}$, en los dos módulos de la derecha, se tienen cuatro viviendas, un módulo de una vivienda y el otro con tres viviendas unifamiliares.

De igual manera, la represa se ubica fuera del casco principal hacia el sureste. Como lo muestra la figura 9, es un elemento de infraestructura hidráulica con planta de forma rectangular, donde el agua bajaba del norte del asentamiento y, de ahí, continuaba hasta la hacienda a través del acueducto, sin embargo, no quedan vestigios de la compuerta de paso.

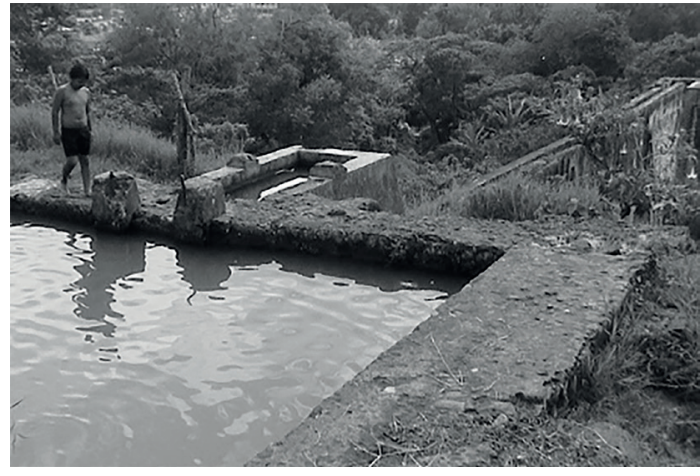

FIGURA 9. REPRESA DE LA HACENDA DE PACHO [2011).

FUENTE: ELABORACIÓN DEL CATÁLOGO NACIONAL DE MONUMENTOS HISTÓRICOS DEL MUNICIPIO DE EMILLANO ZAPATA, NAH.

El acueducto (figura 10) está hecho de mampostería de piedra y aplanado, se forma por tres arcos: dos de forma ojival y uno de medio punto. A pesar de sus buenas condiciones, no se usa hoy en día. Contiguo a esta construcción hidráulica se ubica el cuarto de máquinas.

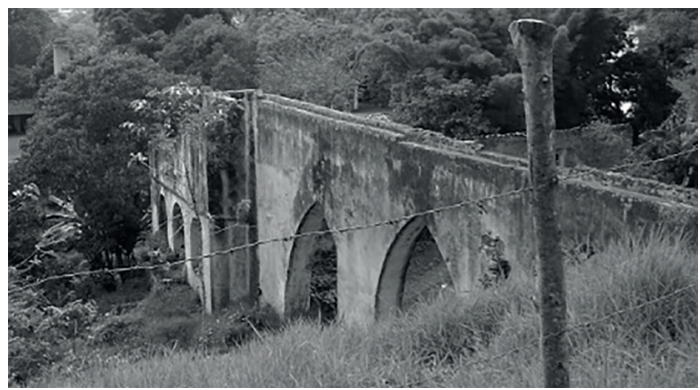

FIGURA 10. ACUEDUCTO DE LA HACIENDA DE PACHO (2011).

FUENTE: ELABORACIÓN DEL CATÁLOGO NACIONAL DE MONUMENTOS HISTÓRICOS DEL MUNICIPIO DE EMILLANO ZAPATA, INAH.

\section{ESTUDIO TIPOLÓGICO DE LA HACIENDA DE NUESTRA SENORA DE LOS REMEDIOS}

En los primeros alcances al análisis formal de la hacienda, se determinó que es un conjunto agrupado con una distribución concéntrica radial y que la fuente monumental, al centro del patio, funciona como punto focal y a partir de ella se distribuyen los espacios divididos en cuatro usos principales: la vivienda de los obreros (verde), la vivienda del hacendado (azul), el área productiva (naranja) y la capilla (rojo) (figura 11). La capilla, además, funge como remate visual desde la calzada de acceso al conjunto y se avista entre la vegetación al encontrarse en un punto más alto del asentamiento.

El jardín central de la hacienda es un patio de control del conjunto, quien se encuentre en esta zona puede avistar lo que sucede, tanto en la casa de los trabajadores como en la zona de producción, lo que se celebra en la capilla y, a su vez estar al pendiente de lo que se requiera en la casa del hacendado (figura 12). 


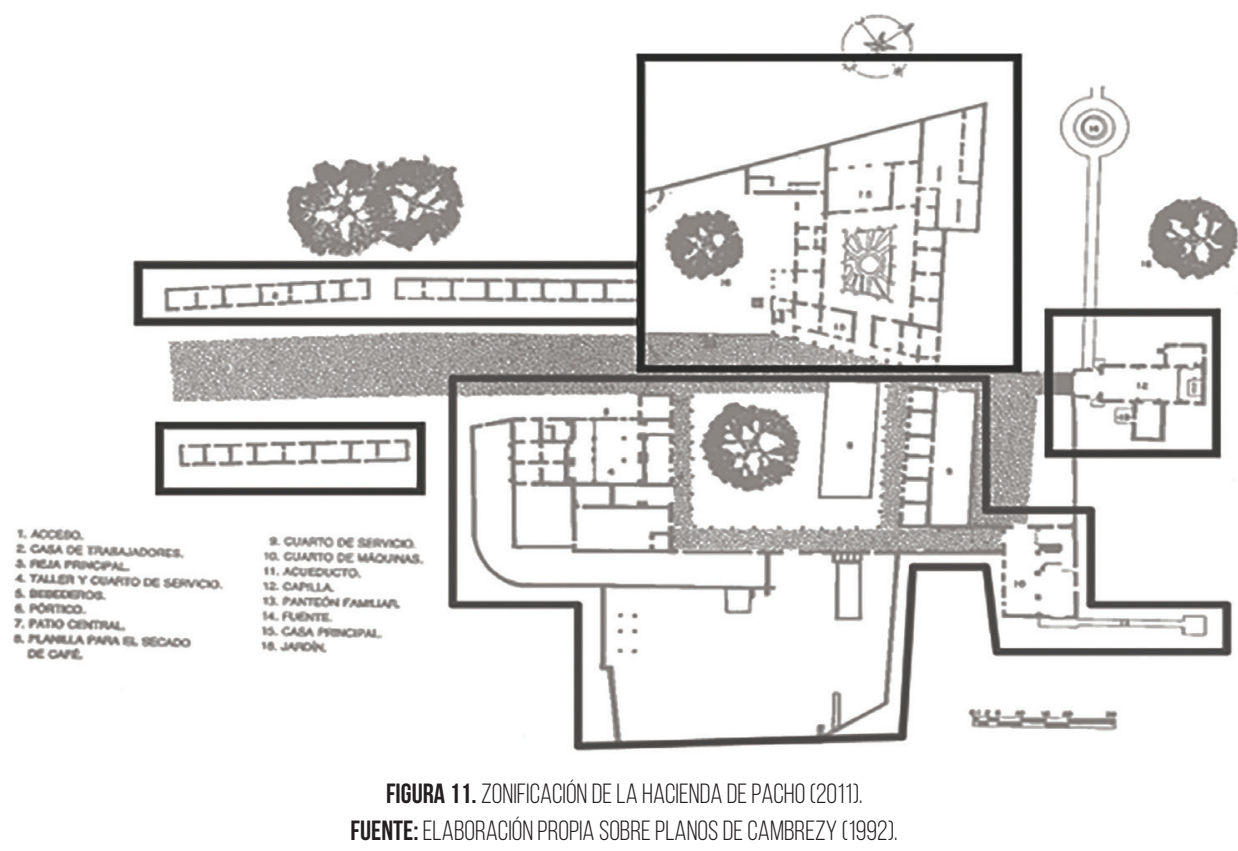

La casa principal tiene una distribución concéntrica, todas las habitaciones, además de tener vinculación contigua, tienen su acceso principal desde el pasillo interior, que funge como espacio semi-abierto entre ellas y el patio interior, siendo este último, el resultante de la disposición espacial de la vivienda.

En la figura 13, se observa que el espacio semi-público (rojo) es el vínculo distribuidor entre el espacio público (amarillo) y el espacio privado (verde). Los espacios públicos rodean el conjunto principal sin un orden entre ellos sino subordinados a la distribución interna de la hacienda. En cambio, el espacio semipúblico forma un eje al que se unen las dos viviendas del conjunto.
La Capilla de Nuestra Señora de los Remedios cumple con los rasgos arquitectónicos de otras más de la región de Xalapa. El partido arquitectónico es muy similar, nave rasa de carácter austero, más larga que ancha, con un sólo acceso central al frente y cubierta a dos aguas. La fachada tiene constantes que se han encontrado en la zona, mientras el acceso principal concluye en un arco de medio punto y el remate en espadaña de tres campanarios (figura 14).

Las aproximaciones del estudio, hoy en día, dan como resultado una clasificación de las constantes, que serán la base de un estudio posterior sobre tipología arquitectónica, y, a su vez, permitirán la comprensión del complejo sistema de haciendas.

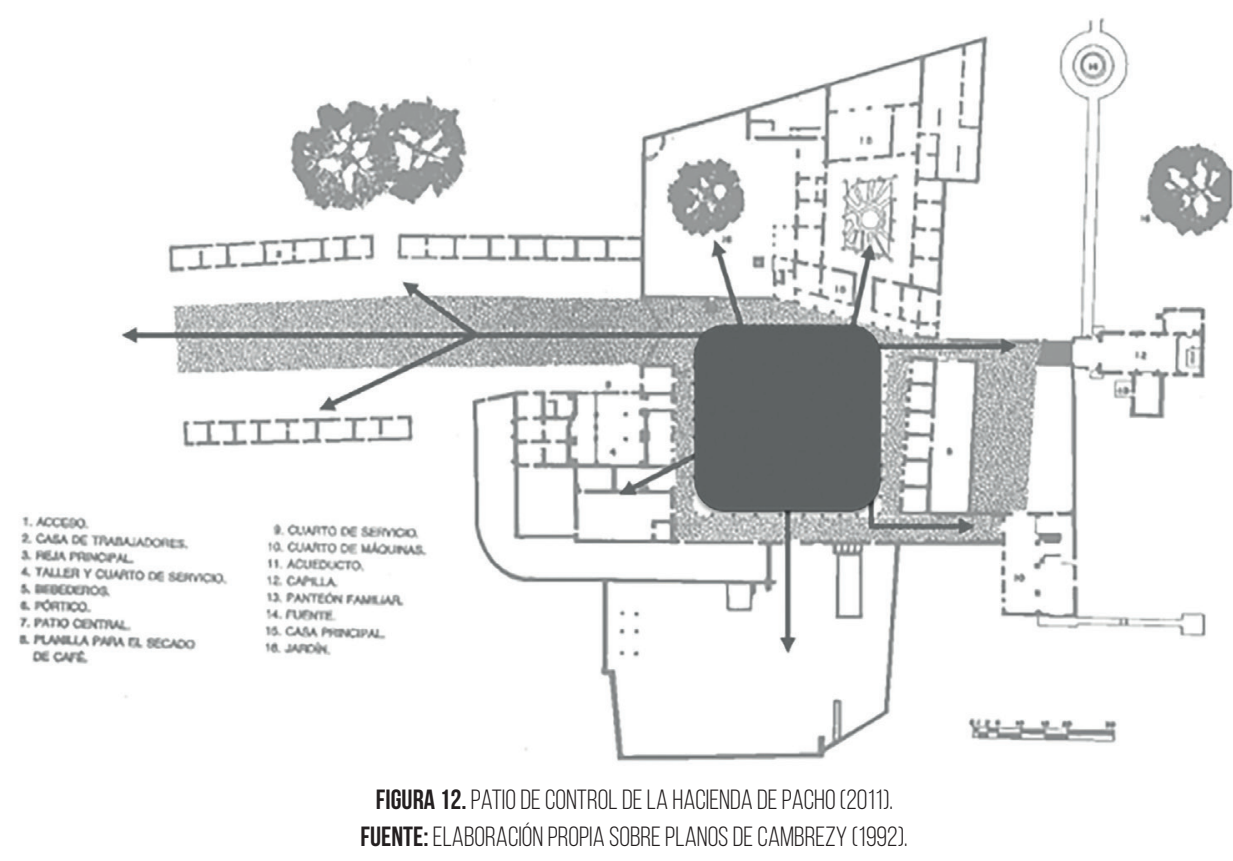




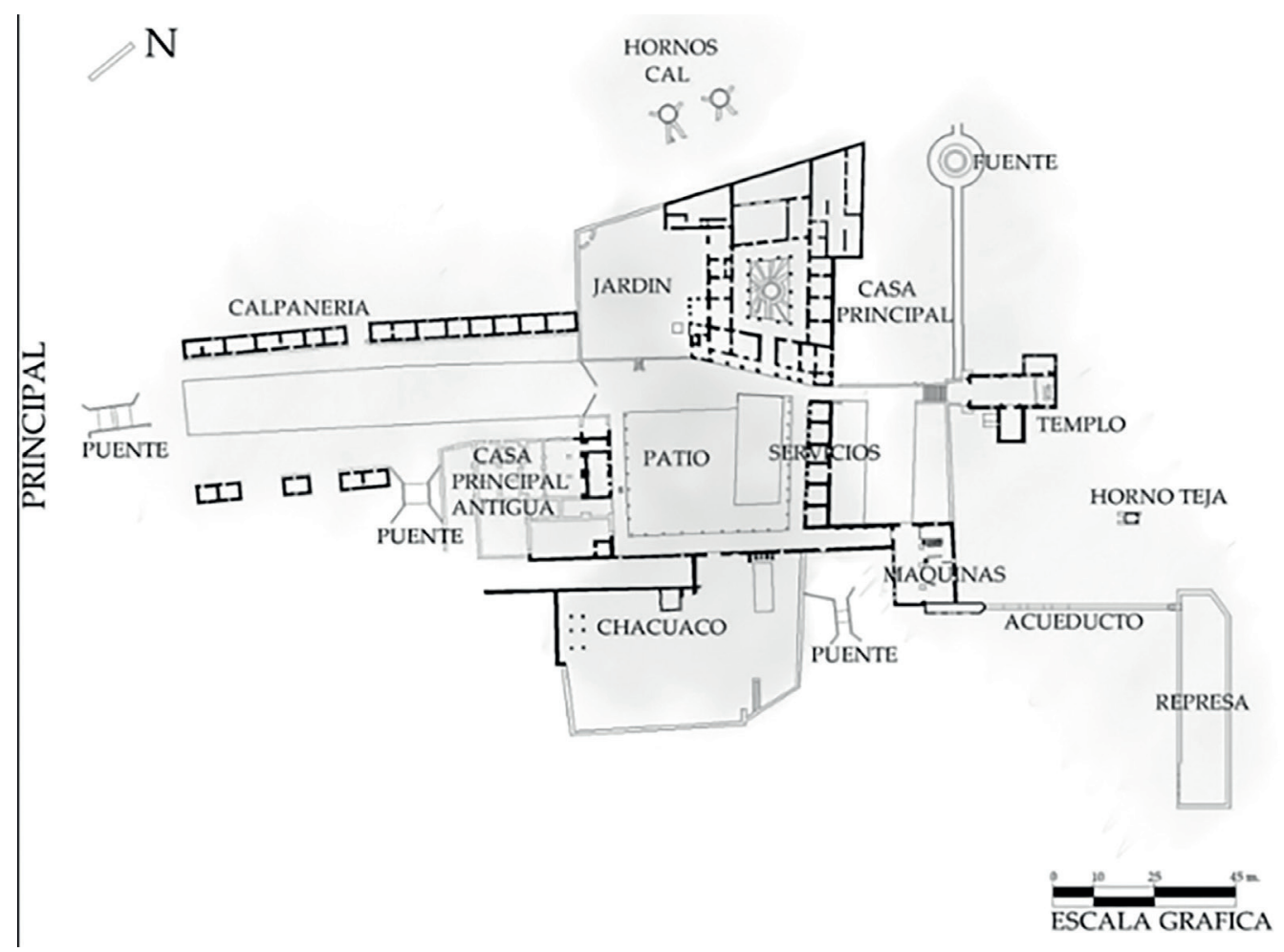

FIGURA 13. DISTRIBUCIÓN DE ESPACIOS PÚBLLCOS, SEM PÚBLICOS Y PRIVADOS

FUENTE: ELABORACIÓN PROPIA SOBRE PLANOS DE CAMBREZY (1992].
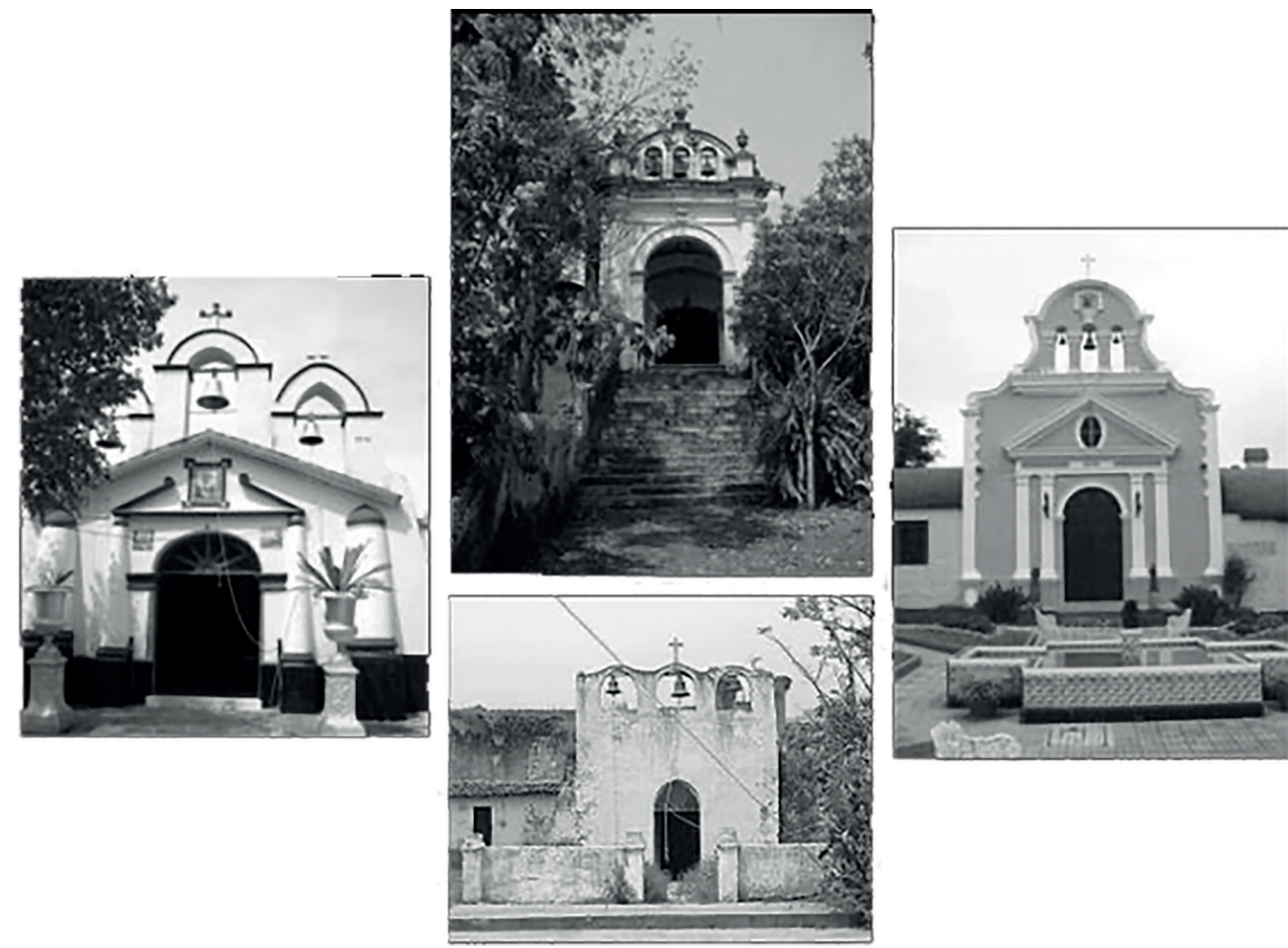

FIGURA 14. CAPILLAS CON ESPADAÑA SUPERIOR. EN ORDEN: ALMOLONGA, PACHO NUEVO, SAN LORENZO Y LUCAS MARTIN. FUENTE: VARIAS 


\section{CONCLUSIONES}

La hacienda, como ente de desarrollo económico de México, ha permanecido presente como un símbolo de identidad comunitaria por su majestuosidad en la construcción, donde sus espacios y partido arquitectónico integran una composición, cuyo reflejo en la actualidad representa la apropiación de un espacio donde se manifiesta un sistema organizativo de la hacienda, que permaneció estable por cerca de 400 años, y representan, desde el medio económico, temporal y cultural de la etapa histórica de México, cuya construcción es el reflejo de un desarrollo socialmente cuestionable, pero de progreso económico del país y de la región en donde se asienta el inmueble. Por ello, se resalta la importancia de considerar a la hacienda como un símbolo de identidad, ya que, si bien, surgió como una entidad económica autosuficiente y la vida de los habitantes de la comunidad circundaba en torno a este espacio, el sentido distinto al de su origen destaca un elemento representativo de la comunidad a la que pertenece.

En la actualidad, la hacienda se emplea para la celebración de fiestas privadas, ya que su construcción se encuentra en sobresaliente estado de conservación con mobiliario original, heredado a través del tiempo por la familia Gutiérrez (camas, cuna, cuadros, pinturas y enceres domésticos). Es importante destacar que las instalaciones del inmueble han sido restauradas poco a poco por la dueña para conservar su diseño original.

El crecimiento de la zona metropolitana de Xalapa ha consumido el entorno paisajístico del asentamiento y, sin lugar a duda, en unas décadas más será absorbida por la mancha urbana. El vínculo que aún poseen los pobladores de Pacho Nuevo con la Hacienda de Nuestra Señora de los Remedios es parte de la cosmovisión local, lo que conlleva a afirmar que no se puede entender la identidad de esta comunidad sin la intervención de este conjunto, como un actante de la vida cotidiana; además de ser el origen de este pequeño poblado que ha soportado el transcurso del tiempo y se ha adaptado a los tiempos actuales sin dejar atrás los elementos funcionales y arquitectónicos que la hacen única en la región. Lo anterior releva la importancia de la arquitectura del inmueble y su relación con el contexto como vínculo de la identidad con la comunidad y como símbolo imperioso de una etapa histórica del México virreinal en la región de Pacho Nuevo. 


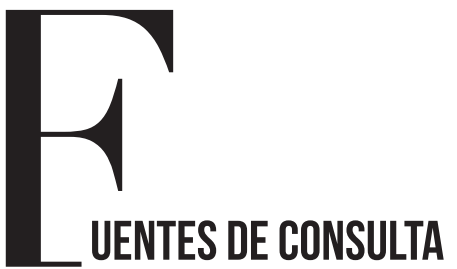

Bermúdez, G. (1988), "La formación de las haciendas en la región de Jalapa 1580-1630", La Palabra y el Hombre, núm. 67, pp. 67-74. Disponible en https://cdigital.uv.mx/bitstream/ handle/123456789/2048/198867P67.pdf?sequence=2\&isAllowed=y, consultado el 30 de septiembre de 2020.

Cambrezy, L. (1992), Crónicas de un territorio fraccionado: de la hacienda al ejido; Centro de Veracruz, Larousse, México.

Franco, E. (2010), "Arquitectura Colonial: Haciendas en México. Sistemas de Producción y Clasificación. [1530-1850 D.c.]", Apuntes Digitales y Cuestionarios por Clase. Universidad Autónoma del Estado de Hidalgo. Instituto de Ciencias Básicas e Ingeniería/Licenciatura en Arquitectura. Disponible en https://www.uaeh.edu.mx/docencia/P_ Lectura/icbi/asignatura/HistoriaMex27.pdf, consultado el 05 de septiembre de 2020 .

García, M., E. (2011), Las Haciendas en México. Universidad Veracruzana.Disponibleenhttps://cdigital.uv.mx/handle/123456789/32165, consultado el 25 de septiembre de 2020 .

García, G., S. (1983), "Hacienda de Pacho", La Palabra y el Hombre, núm. 45, pp 27-35. Disponible en http://cdigital.uv.mx/ handle/123456789/1579, consultado el 30 de septiembre de 2019.

Instituto Nacional de Antropología e Historia (INAH) (2011), Catálogo Nacional de Monumentos Históricos del municipio de Emiliano Zapata, INAH, México.

Laboratorio de Arqueología y Arquitectura de la Ciudad (LAAC) (2016), Conservación y restauración del patrimonio histórico arquitectónico y arqueológico. Disponible en https://www.eea.csic.es/ laac/investigacion-laac/conservacion-y-restauracion-del-patrimoniohistorico-arquitectonico-y-arqueologico/, consultado el 05 de septiembre de 2020 .

Meyer, J. (1992), Prólogo en L. Cambrezy, Crónicas de un territorio fraccionado: de la hacienda al ejido; Centro de Veracruz. Larousse, México, pp. v-vIII.

Organización de las Naciones Unidas para la Educación, la Ciencia y la Cultura (UNESCO) (1968), Recomendación sobre la conservación de los Bienes Culturales que la ejecución de obras públicas o privadas pueda poner en peligro. Disponible en http://portal.unesco.org/es, consultado el 05 de septiembre de 2020.

Warman, A. (2003), La reforma Agraria Mexicana: Una visión de largo Plazo. Disponible en http://www.fao.org/3/j0415t/j0415t09.htm, consultado el 05 de septiembre de 2020 . 